\title{
Comprehensive family hygiene promotion in peri-urban Cape Town: Gastrointestinal and respiratory illness and skin infection reduction in children aged under 5
}

\author{
E C Cole, M Hawkley, J R Rubino, B T Crookston, K McCue, J Dixon, T Maqelana, J Cwayi, C Adams, J Kim
}

Department of Health Science, Brigham Young University, Provo, UT, USA

E C Cole, DrPH

M Hawkley, MPH

B T Crookston, $\mathrm{PhD}, \mathrm{MPH}$

Reckitt Benckiser Inc., Montvale, NJ, USA

J R Rubino, MA

$\mathrm{K} \mathrm{McCue}, \mathrm{MS}$

Department of Family and Preventive Medicine, University of Utah, Salt Lake City, UT, USA

$\mathrm{J} \mathrm{Kim,} \mathrm{PhD}$

Center for Economic Self-Reliance, Brigham Young University, Provo, UT, USA

J Dixon, EdD

Phublani Consultants, Cape Town

T Maqelana

Uvimba Health, Cape Town

J Cwayi

C Adams

Corresponding author: ECCCole (gene_cole@byu.edu)

Background. Hygiene promotion has become increasingly important to public health policy makers as an illness reduction strategy. The primary aim of this study was to assess the differential effects of hygiene education alone compared with hygiene education plus hygiene products on the reduction of target illnesses/infections.

Aims and methods. We hypothesised that a participatory learning and action (PLA) family hygiene education approach plus the regular use of hygiene products could result in marked reduction of morbidity in children aged under 5 years. Population groups in two separate geographical areas were utilised (685 households). Each group consisted of a government (Reconstruction and Development Programme, RDP) housing community (indoor tap/flush toilet) and an informal (INF) housing community (communal tap/latrines). Illness data were gathered in both groups before hygiene education was introduced in June - November 2006 (study baseline) and for the same period in 2007 (study follow-up) after one group had received hygiene education only (control) and the other group hygiene education plus hygiene products (intervention). Facilitators from the communities monitored symptoms weekly and reinforced disease prevention behaviours, focusing on handwashing and bathing with soap, cleaning toilet/food surfaces, and treating skin problems with antiseptic.

Results. Children aged under 5 years in all communities had significant reductions in gastrointestinal and respiratory illnesses and skin infections over time. At study follow-up the control RDP community with hygiene education only was 2.46 times more likely to experience gastrointestinal illnesses (hazard ratio (HR) 2.46, 95\% confidence interval (CI) 1.17 - 4.91) and 4.56 times more likely to experience respiratory illnesses (HR 4.56, CI 1.97 - 10.54) at study follow-up than the intervention group. There was no statistical difference in the incidence of skin infections for children living in RDP housing. The INF community with hygiene education only was 1.64 times more likely to experience gastrointestinal illnesses (HR 1.64, CI 1.32 - 2.03), 4.62 times more likely to experience respiratory illnesses (HR 4.62, CI $4.19-5.09$ ) and 1.29 times more likely to experience skin infections (HR 1.29, CI 1.26 - 1.32) than the intervention group.

Conclusion. While hygiene education alone resulted in meaningful reductions in gastrointestinal and respiratory illness and skin infections in children aged under 5 years across all communities, families with hygiene education plus consistent use of provided hygiene products had greater reductions. 
Diarrhoea and acute respiratory infections (ARIs) are a major burden of infectious disease for the world's child population. ${ }^{1}$ Eighty-eight per cent of the estimated 1 billion episodes of diarrhoea each year can be directly attributed to harmful environmental factors such as unsafe water and inadequate sanitation and hygiene. ${ }^{2-3}$ Likewise, 150 million cases of ARI, resulting in the greatest number of childhood deaths per year, are caused by disease agents that thrive in unsanitary environments. ${ }^{4-5}$ Handwashing (with soap, and at critical times) is repeatedly highlighted in the literature as one of the most important hygiene behaviours to be promoted when seeking to decrease illness and death among children..$^{6-8}$ While previous studies have confirmed the effectiveness of handwashing in reducing diarrhoea in developing countries, few have been comprehensive in addressing the gastrointestinal, skin and respiratory illnesses that mark the burden of infectious disease for children aged under 5 years. Hygiene promotion has become increasingly important to public health policy makers as a low-cost disease reduction strategy. ${ }^{9}$ In the literature supporting hygiene promotion as an effective public health intervention, the need for better-designed programmes to address the full impact of hygiene promotion on overall individual and family health is also emphasised. ${ }^{10}$

One of the ways to address family and individual hygiene is through the use of participatory learning and action (PLA) research, which is a community development approach whereby facilitators work with communities to help them analyse their needs, identify solutions to fill those needs, and develop and implement a plan of action. It focuses on grass-roots mobilisation of communities by empowering them to explore their specific health needs and set priorities, plan together, implement or act together, and finally evaluate and reflect together. ${ }^{11}$ Within this approach, all participants become researchers, teachers and learners simultaneously.

Addressing illness through PLA family hygiene behaviour change education plus the regular use of hygiene products could result in marked reduction of morbidity and mortality in children aged under 5. The primary aim of this study was therefore to assess the differential effect of hygiene education alone compared with hygiene education plus hygiene products on the reduction of target illnesses/infections.

\section{Methods}

This study consisted of three major components: (i) partnership formation and participant selection; (ii) hygiene education/product distribution development and implementation; and (iii) data collection and analysis.

\section{Partnership formation and participant selection Health and Hygiene Promotion Partnership formation}

This study was designed and carried out within the framework of the Cape Town Health and Hygiene Promotion Partnership (HPP), a community-based non-profit organisation established in 2005 by joint effort between members of the participating housing communities, Brigham Young University (BYU) and Reckitt Benckiser, Inc., with the approval of the Cape Town City Health Department and with assistance from the Cape Peninsula University of Technology and the University of the Western Cape.

As priorities, strategies, regulations, sustainability and ethical considerations for the project were discussed within the partnership, there was unanimity that the hygiene promotion and disease reduction strategy should actively involve community members in decision making and all aspects of implementation. This would foster a sense of ownership of the project, contribute to the success of the behaviour change efforts, and, it was hoped, lay the foundation for long-term sustainability of hygiene practices and communicable disease reduction.

\section{Community selection and participant profile}

Household participants consisted of families in four lower socioeconomic communities living in Reconstruction and Development Programme (RDP) housing and informal settlements (INF) on the Cape Flats - the historically impoverished, outlying areas east of the city centre of Cape Town, South Africa, recognised by the Cape Town City Health Department as particularly challenged by diarrhoea and respiratory illnesses in children.

Participants were primarily of black African (Xhosa) origin. Candidate communities were identified through the HPP partnership on the basis of a sound community organisation (e.g. housing authority, finance group), not being scheduled for major renovations, presenting low risk with regard to safety issues, and being receptive and committed to long-term study.

From a large population sample (5 791 people in 1292 households), 685 households were identified that met the study criteria of having at least one child under 5 years of age and were willing to participate in the study.

Study groups in two separate geographical areas were utilised. Each group consisted of a government (RDP) housing community and an informal (INF) housing community. RDP housing consisted of permanent individual block homes built by the owners or by the government's housing programme. The majority had indoor plumbing with a single clean-water tap and flush toilet. These were represented by the Dunoon and Triangle communities.

INF housing consisted typically of wooden shacks and other squattertype dwellings constructed from a variety of scavenged materials. Communities had communal clean-water taps, with sanitation in the form of communal latrines and/or indoor buckets. Such housing was represented in the study by the communities of Kwa 5 and Sweet Home.

\section{Team leader and facilitator selection}

Three mobilisers from the local communities were recruited as the study team leaders. They then worked with the study's principal investigators to finalise an appropriate cultural approach to the education and topics discussed in the following section. Their responsibilities included training community facilitators in PLA education, product use, and overall research activities. Sixty-four facilitators ( 62 female, 2 male) were recruited from the participating communities to collect illness symptom data and to teach and train assigned cluster groups (20 - 25 families) in hygiene education and product use. In addition to collecting symptom data on all members of each household weekly, facilitators served as a recognised source of health-related information for their community. Facilitators attended biweekly training and reflection meetings throughout the 2-year programme to learn how to make weekly household visits, collect family member illness symptom data, conduct and reinforce participatory hygiene education, and carry out monitoring, evaluation and data reliability tasks.

\section{Hygiene education/product distribution development and implementation Hygiene education development}

A hygiene promotion education programme was designed using PLA research methodology. This community empowerment approach was established not only for conducting formative research but also to be used in the lesson plans themselves. Prior to baseline, facilitators implemented PLA in the communities to identify common communicable illnesses and infections and to develop appropriate symptom data collection forms. Formative research information on cultural and social norms, perceptions of illness and risk, and conditions of home and community environments was obtained through group approaches. Data collected during this period were used to develop and design culturally appropriate and 
sensitive PLA hygiene education lesson plans for both control and intervention families.

\section{Hygiene education implementation}

The hygiene education developed and implemented in both study groups was comprehensive, going beyond the basic practice of handwashing at critical times with soap (i.e. after defecating, after cleaning a child who has defecated, and before eating and handling food). The hygiene practices taught were: (i) handwashing with soap and water at critical times including additional critical times such as after handling body fluids or blood, after touching a pet, after playing outside, after gardening, etc.; (ii) bathing the body at least three times a week; (iii) properly cleaning wounds with antiseptic; (iv) cleaning/disinfecting household surfaces at critical times; ( $v$ ) using and safely storing hygiene products; (vi) safe handling and storage of food; (vii) insect and rodent control; and (viii) proper household waste disposal.

Trained community facilitators conducted hygiene education lessons at their cluster member group meetings and reinforced the hygiene message during weekly household visits. Education in good hygiene practices was implemented through six personal and home hygiene lessons followed by six environmental hygiene lessons. At the end of each unit, a summary lesson was taught. After each lesson, cluster members received a simplified version to teach their families. Each home lesson included a discussion guide, game-like activities and guidelines for organising the family to carry out the actions and report their progress. Home lessons extended the support structure of the programme beyond the cluster level to the home level, where behaviour change would have its major impact. During the follow-up period, the participants engaged in reinforcing hygiene practices with each other and sharing the personal and home hygiene lessons with others outside the study (e.g. neighbours, school and church groups, NGOs, etc.).

\section{Distribution development and implementation of hygiene products}

Study intervention participants received personal and household hygiene products to use in conjunction with the hygiene education described above. Each product intervention household was initially supplied with six bars of soap, two bottles of surface cleaner/ disinfectant and one bottle of skin antiseptic, with a re-supply system to ensure that hygiene products were always available to the households. These products were selected because they targeted common routes of exposure to illness and infection that included hand, body and surface contamination.

The soap (PCMX 0.3\%) was to be used for all handwashing and bathing. The surface cleaner (benzalkonium chloride $0.074 \%$ ) was to be used for cleaning and decontamination of surfaces in toilet and food preparation areas, as well as commonly recognised fomites in other household locations (such as door handles, baby changing areas, etc.). The participants were instructed to use the antiseptic (chloroxylenol 4.8\%) at a 1:20 dilution for skin scratches, cuts and minor wounds.

\section{Study control and intervention}

Dunoon (RDP) and Kwa 5 (INF) were selected as the study control group and received reinforced hygiene education. They were not provided with hygiene products, but could acquire them if desired through their own motivation and resources. Triangle (RDP) and Sweet Home (INF) were selected as the study intervention group and received hygiene products along with reinforced hygiene education. Each paired group was geographically separated by $40 \mathrm{~km}$ to prevent cross-contamination. Assignment of groups as study control and intervention was done in conjunction with guidance from city health leaders. Characterisation of the study households according to the four participating communities is shown in Fig. 1.

\section{Data collection and analysis}

\section{Household characterisation survey}

A household survey was administered in the autumn of 2006 that consisted of $>200$ items and addressed the key areas of demographics, household inventory, sanitation practices, water sources, storage and use, kitchen hygiene, personal hygiene, and soap and hygiene product use.

\section{Baseline illness data collection (2006)}

Baseline illness data were collected for 1 year before hygiene education and product distribution implementation. This was the 'non-hygiene education' phase. Communicable illnesses most common to the communities and also recognised as challenges to children's health globally were identified by HPP team leaders, facilitators and cluster members, as shown in Table 1. Illnesses were further characterised according to body parts and related symptoms. The tools used for collecting these data included the Sunday Family Health Chart and the Burden of Illness Respiratory, Gastrointestinal and Skin forms. The Sunday Family Health Chart was designed to record symptoms in relation to body parts. Each Sunday, trained cluster members marked on their family chart where their families had experienced illness according to body part during the week. Based on which body parts had been marked on the Sunday Family Health Chart, the facilitator would administer the corresponding Burden of Illness form. Facilitators visited the homes weekly, verified the symptoms for each household member and recorded them on the illness data collection forms, which were scanned into a database using a customised software program. Subsequent analysis of the symptom data provided classification of information according to illnesses and infections.

Baseline data were collected weekly from June through November 2006 in both groups. The period June - November was significant, as it constituted a representative seasonal approach to both warm and cool seasons. The data collection process and forms were piloted to households for understanding and data reliability before baseline data collection.

\section{Follow-up illness data collection (2007)}

Follow-up symptom and hygiene behaviour data were collected and monitored from June to November 2007, after hygiene education and product implementation. Hygiene promotion education consisting of handwashing and home hygiene was initiated within communities in March 2007, providing 3 months for behaviour change introduction and adoption of personal and home hygiene behaviours prior to weekly illness monitoring in the follow-up period.

\section{Behaviour change monitoring}

To assess behaviour change at the home level, a monitoring form was completed by the facilitators during home visits. Recorded on this form were programmatic data such as cluster attendance, reception of cluster education, home lessons at the family level and key observations related to weekly product usage and safe and proper storage of soap, cleaning products and antiseptic in the home. Data regarding the adoption of new behaviours and practices introduced in the hygiene promotion lessons were also recorded.

\section{Product use monitoring}

The initial household survey showed that most households had allpurpose bar soap, dishwashing soap or cleaning products (including bleach). Product use was monitored and recorded weekly on the monitoring form during weekly facilitator household visits to collect symptom data, reinforce hygiene behaviours, and physically observe the presence and use of products in both study groups.

Facilitators ensured that intervention group cluster members had sufficient products for the uses of their household weekly. A distribution centre was set up and managed in the intervention 


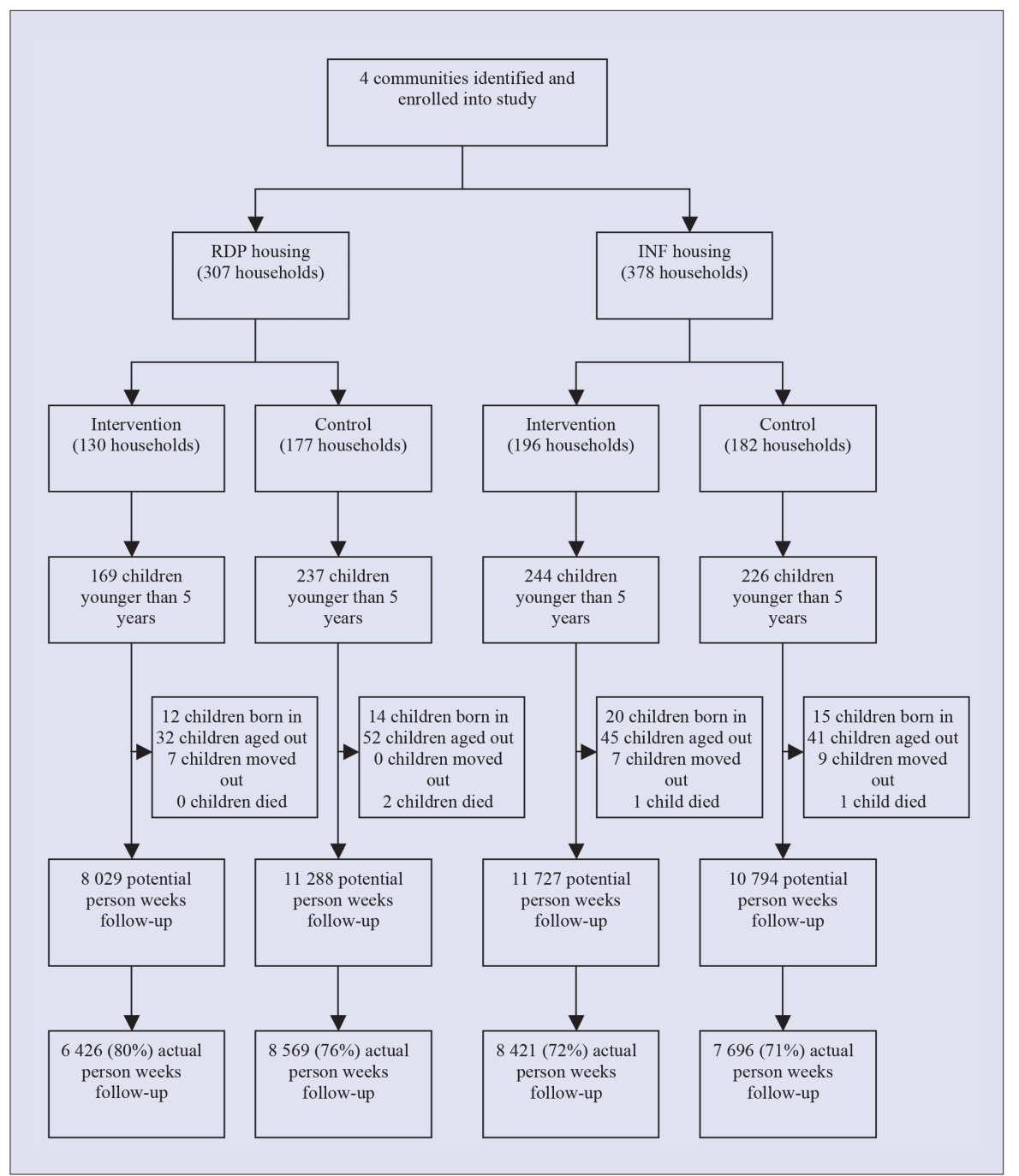

Fig. 1. Community intervention and control assignment and follow-up.

communities for re-supply. Cluster members had to return empty bottles and slivers of soap to obtain a new supply.

\section{Ethics}

Heads of households provided written informed consent. As BYU had responsibility for co-ordinating the study, it was required that informed consent and study protocol receive BYU Institutional Review Board approval. The team leaders from the communities together with the study investigators developed culturally appropriate consent forms in both English and Xhosa.

\section{Data reliability and verification}

A comprehensive data quality assurance and control system was established to verify all quantitative illness and other monitoring data. The collected data were scanned into the database and verified by an automatic data entry program process. Data were recorded automatically through an individual participant barcode recognition system. Household facilitator visits were also recorded manually as a check against the result of a host of distinct differences between housing types (RDP and INF), all analyses were stratified by housing type.

Cox proportional hazard models were used to compare time to case of illness for intervention communities versus study control while adjusting for time (baseline v. followup) and socio-demographic factors that showed association with outcomes of interest and were significantly different between the two communities. Cox regression models were used because the unit of observation was the individual subject rather than events per person year of observation. Recurrent events over time were modelled. A model was produced for each housing type and each disease grouping within the housing type. Interaction was evaluated and backward selection was performed to identify statistically significant confounders. To reflect potential within-cluster correlation (i.e. positive or negative correlation in outcomes) of subjects within the same communities, a robust cluster variance approach was used with regression models to control the correlation of residuals. Because the Cox models are based on the assumption of proportionality, post-estimation was conducted to examine whether or not the assumption is violated in the models. Global tests for proportionality were conducted and each covariate was examined to assess which variables violated the assumption. Models in INF housing on gastrointestinal and skin diseases violated the assumptions and were therefore modified. Furthermore, some participants had interval truncations that might have influenced the number of participants at risk calculations. The interval gaps were considered in the analysis. Cox hazard models give a confidence interval (CI) for results in each study, allowing the results to be deemed statistically significant. All Cox regression models controlled for a number of potential confounders. Confounders were retained based on estimate significance and model assumptions in Cox regressions. Variables examined as confounders included marital status, language, employment status, race, children in school or crèche, maternal education, assets and services (e.g. TV, radio, electricity, number of rooms in home, fuel type, toilet, water source), and number of children in the home.

\section{Results}

\section{Participant profiles}

Summary demographic characteristics, as provided by a woman in each household, are shown in Table 2. Overwhelmingly, the women were Xhosa, had some education and were literate in their mother tongue; were not likely to be working even part-time; were receiving governmental support of some type; and had children in school and in crèche (day care). They were as likely to be unmarried 
Table 1. Illness definitions according to symptoms

Upper respiratory tract

Cold

- Blocked nose and/or running nose AND

- Dry cough or cough with phlegm

Otitis (acute ear infection)

- Pain in ear/baby pulls on ear AND/OR

- Running ear

Pharyngitis/sore throat/strep throat

- Swollen throat glands AND

- Pain when talking or swallowing AND/OR

- White spots on back of throat

Flu

- Body aches AND

- Low-grade fever or high fever and chills AND

- Cough with phlegm or dry cough

\section{Lower respiratory tract}

Pneumonia

- High fever and chills or low-grade fever AND

- Cough with phlegm or dry cough AND

- Tight chest and/or shortness of breath/fast breathing AND/OR

- Chest pain/hurts to breathe

Asthma

- Wheezing AND

- Shortness of breath/fast breathing or tight chest

\section{Gastrointestinal}

Diarrhoea

- $\geq 3$ loose stools in 24 hours AND/OR

- Watery and/or bloody diarrhoea AND diarrhoea for $<7$ or $>7$ days

Severe diarrhoea

- Diarrhoea lasting more than 7 days AND

- Dehydrated and/or loose skin and/or sunken fontanelle

Nausea and vomiting

- Nausea (queasiness) and vomiting

\section{Skin diseases}

Impetigo

- Blisters/sores primarily on arms/hands, legs and face (can occur anywhere)

- Intense itching and burning

Eczema

- Itchy, scaly, oozing, crusty skin, mostly on hands and face

Scabies

- Itchy rash, primarily on armpits, groin, beltline and nipples

Ringworm

- Round, itchy scaly patches

Boil

- Swollen, painful lump under the skin

Abscess

- Infected cut or wound (painful, oozing pus)

Pink eye

- Watery, very pink eyes, crusty discharge as married, received prenatal care, had their last child born in a hospital, breastfed their last child, and owned a cell phone, regardless of the community in which they resided. Most households reported the use of paraffin as heating fuel, problems with mould on walls or ceilings, and problems with rodents. PLA research activities within each study group confirmed diarrhoeal and respiratory illnesses, and skin problems as the most prevalent infectious illnesses.

\section{Seasonal illness data}

Seasonal incidences of gastrointestinal and respiratory illnesses and skin infections per 100 person weeks are shown in Table 3. 2006 baseline data were generated from weekly reporting of illness symptoms for family members in each household. RDP housing communities typically had lower rates of gastrointestinal and respiratory illnesses and skin infections than INF households. This is to be expected in view of the fact that INF households have greater challenges to personal and family hygiene owing to restrictions associated with clean water (communal tap with home storage) and sanitation (latrines and in-home bucket toilets).

Similar to baseline data, 2007 follow-up incidence data for gastrointestinal and respiratory illnesses were lower for RDP households (for both study groups) than INF ones, with the exception of skin infection incidence data, where rates were slightly higher in the RDP households than the INF ones. No rationale for this is surmised, although the incidence rate reduction differences for skin infections in both housing types during the follow-up phase versus the baseline phase were shown to be statistically significant $(p<0.0001)$. Correspondingly, incidence rate reductions for skin infections in INF households, both intervention (74.6\%) and control (77.1\%), are impressive. This correlates with anecdotal reports from women across all the communities that regular washing of skin with soap and water resolved a variety of chronic skin conditions in children, such as impetigo, eczema and rashes of undetermined types. The importance of using an antiseptic to treat minor scratches and wounds must also be recognised as influential in the reduction of skin infections.

Comparative illness reduction differences between control and intervention groups for both RDP and INF housing areas for each illness category are shown in Table 3 . With one exception, as previously noted, the addition of hygiene product use to intensive and reinforced hygiene education resulted in lower incidence rates. High reduction differences for hygiene education plus products for respiratory illnesses in both INF housing (37.8\%) and RDP housing $(24.6 \%)$, as well as skin infection reduction in RDP housing (39.1\%), show that the consistent use of hygiene products has a significant impact on reducing illness incidence.

Cox hazard analysis was completed to assess illness risk potential after controlling for other factors such as age, gender and socio-economic indicators, and to find $95 \%$ CIs for this potential. As dramatically shown by the hazard ratios (HRs) in Table 4, children aged under 5 years in control RDP housing (hygiene education only) were 2.46 times more likely to experience gastrointestinal illnesses (HR 2.46, CI 1.17 - 4.91) and 4.56 times more likely to experience respiratory illnesses (HR 4.56, CI 1.97 - 10.54) at the end of study follow-up than their intervention (hygiene education + products) counterparts. However, there was no statistical difference in the incidence of skin infections for children living in RDP housing. Children in control INF housing 
Table 2. Baseline household characteristics by group

\begin{tabular}{|c|c|c|c|c|c|c|}
\hline Characteristic & $\begin{array}{l}\text { RDP } \\
\text { intervention } \\
(n=130)\end{array}$ & $\begin{array}{l}\text { RDP control } \\
(n=177)\end{array}$ & Statistics & $\begin{array}{l}\text { INF } \\
\text { intervention } \\
(n=196)\end{array}$ & $\begin{array}{l}\text { INF control } \\
(n=182)\end{array}$ & Statistics \\
\hline Persons per household, mean (SD) & $5.7(1.8)$ & $5.4(2.2)$ & 0.1129 & $4.5(1.6)$ & $4.4(1.7)$ & 0.5043 \\
\hline Age, years, mean (SD) & $2.0(1.5)$ & $2.3(1.4)$ & 0.0641 & $2.0(1.4)$ & $1.9(1.4)$ & 0.5301 \\
\hline Children $<5$ per household, mean (SD) & $1.4(0.7)$ & $1.4(0.7)$ & 0.6128 & $1.3(0.6)$ & $1.3(0.6)$ & 0.6365 \\
\hline Marital status, $n(\%)$ & & & 0.2698 & & & 0.0789 \\
\hline Married & $72(55.4)$ & $86(48.6)$ & & $100(51.0)$ & $86(47.5)$ & \\
\hline Not married, cohabiting & $8(6.2)$ & $19(10.9)$ & & $29(14.8)$ & $43(23.8)$ & \\
\hline Not married, living alone & $50(38.5)$ & $72(40.6)$ & & $67(34.2)$ & $52(28.7)$ & \\
\hline Mother tongue, $n(\%)$ & & & 0.1922 & & & 0.0016 \\
\hline Xhosa & $121(93.1)$ & $158(89.2)$ & 0.1922 & $188(95.9)$ & $168(92.2)$ & \\
\hline Afrikaans & $3(2.3)$ & $12(6.8)$ & & $5(2.6)$ & $0(0.0)$ & \\
\hline Other & $6(4.6)$ & $7(4.0)$ & & $3(1.5)$ & $14(7.8)$ & \\
\hline Currently working for money, $n(\%)$ & & & 0.1083 & & & 0.1983 \\
\hline Yes & $70(53.9)$ & $79(44.6)$ & & $62(31.8)$ & $69(38.1)$ & \\
\hline No & $60(46.1)$ & $98(55.4)$ & & $134(68.2)$ & $113(61.9)$ & \\
\hline Receives governmental support, $n(\%)$ & & & 0.0006 & & & 0.0001 \\
\hline Yes & $75(57.8)$ & $135(76.4)$ & & $168(85.6)$ & $121(66.7)$ & \\
\hline No & $55(42.2)$ & $42(23.6)$ & & $28(14.4)$ & $61(33.3)$ & \\
\hline No. of years in current home, $n(\%)$ & & & 0.0001 & & & 0.0003 \\
\hline $0-2$ & $4(3.1)$ & $28(16.0)$ & & $8(4.1)$ & $28(15.4)$ & \\
\hline $3-5$ & $24(18.5)$ & $50(28.0)$ & & $59(30.1)$ & $61(33.5)$ & \\
\hline $6-10$ & $80(61.5)$ & $74(41.7)$ & & $83(42.4)$ & $69(37.9)$ & \\
\hline$>10$ & $22(16.9)$ & $25(14.3)$ & & $46(23.5)$ & $24(13.2)$ & \\
\hline Race, $n(\%)$ & & & 0.0496 & & & 0.2925 \\
\hline Black African & $126(96.9)$ & $162(91.4)$ & & $191(97.4)$ & $180(98.9)$ & \\
\hline Coloured & $4(3.1)$ & $15(8.6)$ & & $5(2.6)$ & $2(1.1)$ & \\
\hline Currently has children attending school, $n(\%)$ & & & 0.1241 & & & 0.6273 \\
\hline Yes & $107(82.5)$ & $133(75.1)$ & & $118(60.2)$ & $114(62.6)$ & \\
\hline No & $23(17.5)$ & $44(24.9)$ & & $78(39.8)$ & $68(37.4)$ & \\
\hline Currently has children attending creche & & & 0.0614 & & & 0.0001 \\
\hline Yes & $94(72.3)$ & $110(62.1)$ & & $93(47.5)$ & $125(68.5)$ & \\
\hline No & $36(27.7)$ & $67(37.9)$ & & $103(52.6)$ & $57(31.5)$ & \\
\hline Received prenatal care during last pregnancy & & & 0.1489 & & & 0.3847 \\
\hline Yes & $108(82.7)$ & $134(75.7)$ & & $132(67.5)$ & $130(71.7)$ & \\
\hline No & $22(17.3)$ & $43(24.3)$ & & $64(32.5)$ & $52(28.3)$ & \\
\hline Ever breastfed last child & & & 0.9051 & & & 0.9426 \\
\hline Yes & $108(82.8)$ & $146(82.3)$ & & $148(75.4)$ & $138(75.7)$ & \\
\hline No & $22(17.2)$ & $31(17.7)$ & & $48(24.6)$ & $44(24.3)$ & \\
\hline Highest level of schooling completed, $n$ (\%) & & & 0.0068 & & & 0.0233 \\
\hline No formal schooling & $7(5.4)$ & $11(6.3)$ & & $12(6.1)$ & $20(11.1)$ & \\
\hline Primary & $35(26.9)$ & $73(41.1)$ & & $90(45.9)$ & $66(36.1)$ & \\
\hline Secondary & $76(58.5)$ & $89(50.3)$ & & $90(45.9)$ & $96(52.8)$ & \\
\hline Tertiary & $12(9.2)$ & $4(2.3)$ & & $4(2.0)$ & $0(0.0)$ & \\
\hline
\end{tabular}


Table 2. Baseline household characteristics by group (continued)

\begin{tabular}{|c|c|c|c|c|c|c|}
\hline Characteristic & $\begin{array}{l}\text { RDP intervention } \\
(n=130)\end{array}$ & $\begin{array}{l}\text { RDP control } \\
(n=177)\end{array}$ & Statistics & $\begin{array}{l}\text { INF } \\
\text { intervention } \\
(n=196)\end{array}$ & $\begin{array}{l}\text { INF control } \\
(n=182)\end{array}$ & Statistics \\
\hline \multicolumn{2}{|c|}{ No. of rooms in home, $n(\%)$} & & 0.0001 & & & 0.0005 \\
\hline 1 & $1(0.8)$ & $111(62.9)$ & & $36(18.4)$ & $55(30.0)$ & \\
\hline 2 & $3(2.3)$ & $38(21.7)$ & & $74(37.8)$ & $84(46.1)$ & \\
\hline 3 & $8(6.2)$ & $16(9.1)$ & & $59(30.1)$ & $34(18.9)$ & \\
\hline 4 & $23(17.8)$ & $4(2.3)$ & & $24(12.2)$ & $9(5.0)$ & \\
\hline$>5$ & $95(72.9)$ & $7(4.0)$ & & $3(1.5)$ & $0(0.0)$ & \\
\hline \multicolumn{2}{|c|}{ Currently have mice or rats, $n(\%)$} & & 0.0001 & & & 0.0001 \\
\hline Yes & $100(77.0)$ & $72(40.9)$ & & $194(98.9)$ & $156(85.5)$ & \\
\hline No & $30(23.0)$ & $105(59.1)$ & & $2(1.1)$ & $26(14.5)$ & \\
\hline \multicolumn{2}{|c|}{ Home heating fuel, $n(\%)$} & & 0.0138 & & & 0.0011 \\
\hline Electric & $17(13.2)$ & $21(12.0)$ & & $29(15.0)$ & $15(8.3)$ & \\
\hline Paraffin & $109(83.7)$ & $132(74.3)$ & & $114(58.3)$ & $92(50.6)$ & \\
\hline Other & $0(0.0)$ & $6(3.4)$ & & $38(19.6)$ & $38(21.1)$ & \\
\hline Nothing & $4(3.1)$ & $18(10.3)$ & & $14(7.2)$ & $36(20.0)$ & \\
\hline \multicolumn{2}{|c|}{ Place of birth of last child, $n$ (\%) } & & 0.0070 & & & 0.0193 \\
\hline Home & $8(6.4)$ & $4(2.3)$ & & $8(4.2)$ & $11(6.2)$ & \\
\hline Hospital & $102(78.4)$ & $162(91.3)$ & & $158(80.8)$ & $159(87.6)$ & \\
\hline Clinic & $20(15.2)$ & $11(6.4)$ & & $29(15.0)$ & $11(6.2)$ & \\
\hline \multicolumn{7}{|c|}{ Owns the following, $n$ (\%) } \\
\hline TV & $118(90.8)$ & $145(81.9)$ & 0.0288 & $129(65.8)$ & $43(23.6)$ & 0.0001 \\
\hline Cell phone & $113(86.9)$ & $152(85.9)$ & 0.7919 & $132(67.4)$ & $130(71.4)$ & 0.3899 \\
\hline Radio & $107(82.3)$ & $122(68.9)$ & 0.0078 & $105(53.6)$ & $111(61.0)$ & 0.1454 \\
\hline Refrigerator & $112(86.2)$ & $130(73.5)$ & 0.0071 & $55(28.1)$ & $12(6.6)$ & 0.0001 \\
\hline \multicolumn{7}{|c|}{ Areas where mould or fungus have been found in home in past year, $n(\%)$} \\
\hline Shoes & $31(23.9)$ & $66(37.3)$ & 0.0123 & $79(40.3)$ & $67(36.8)$ & 0.4859 \\
\hline Clothes & $35(26.9)$ & $75(42.4)$ & 0.0053 & $108(55.1)$ & $49(26.9)$ & 0.0001 \\
\hline Food & $10(7.7)$ & $26(14.7)$ & 0.0597 & $39(19.9)$ & $26(14.3)$ & 0.1485 \\
\hline Walls or ceiling & $106(81.5)$ & $126(71.2)$ & 0.0370 & $129(65.8)$ & $101(55.5)$ & 0.0399 \\
\hline \multicolumn{2}{|c|}{ Main source of drinking water } & & .0016 & & & 0.1412 \\
\hline Communal tap & $36(27.9)$ & $21(12.1)$ & & $191(97.5)$ & $169(92.8)$ & \\
\hline Outside tap & $13(10.1)$ & $28(16.1)$ & & $3(1.5)$ & $11(6.1)$ & \\
\hline Inside tap & $81(62.0)$ & $127(71.8)$ & & $1(0.5)$ & $1(0.6)$ & \\
\hline Other & $0(0.0)$ & $0(0.0)$ & & $1(0.5)$ & $1(0.6)$ & \\
\hline \multicolumn{3}{|c|}{ Reads letter or newspaper in mother tongue, $n(\%)$} & 0.2152 & & & 0.0029 \\
\hline Easily & $117(89.9)$ & $168(94.8)$ & & $178(90.8)$ & $146(80.0)$ & \\
\hline With difficulty & $4(3.1)$ & $4(2.3)$ & & $11(5.6)$ & $30(16.7)$ & \\
\hline Not at all & $9(7.0)$ & $5(2.9)$ & & $7(3.6)$ & $6(3.3)$ & \\
\hline \multicolumn{2}{|l|}{ Toilet facility, $n(\%)$} & & 0.0048 & & & 0.0001 \\
\hline Own flush toilet & $89(68.2)$ & $126(71.3)$ & & $10(5.2)$ & $3(1.7)$ & \\
\hline Shared flush toilet & $41(31.8)$ & $38(21.3)$ & & $90(46.1)$ & $3(1.7)$ & \\
\hline Bucket latrine & $0(0.0)$ & $12(6.9)$ & & $78(39.8)$ & $123(67.6)$ & \\
\hline Pit latrine & $0(0.0)$ & $0(0.0)$ & & $8(4.2)$ & $9(5.0)$ & \\
\hline No facility & $0(0.0)$ & $1(0.6)$ & & $9(4.7)$ & $44(24.0)$ & \\
\hline
\end{tabular}


Table 3. Seasonal incidence and reduction of gastrointestinal, skin and respiratory illnesses for children under age 5 by group

\begin{tabular}{|c|c|c|c|c|}
\hline & $\begin{array}{l}\text { Seasonal 2006*, } \\
\text { incidence }^{\dagger}\end{array}$ & $\begin{array}{l}\text { Seasonal 2007*, } \\
\text { incidence }^{\dagger}\end{array}$ & Reduction, \% & $\begin{array}{l}\text { Reduction } \\
\text { difference }\end{array}$ \\
\hline \multicolumn{5}{|c|}{ Gastrointestinal illnesses ${ }^{\ddagger}$} \\
\hline \multicolumn{5}{|l|}{ Formal housing } \\
\hline Intervention ${ }^{\S}$ & 1.5 & $0.3^{++}$ & 78.6 & \multirow[t]{2}{*}{14.0} \\
\hline Control & 1.9 & $0.7^{++}$ & 64.6 & \\
\hline \multicolumn{5}{|c|}{ Informal housing } \\
\hline Intervention ${ }^{5}$ & 2.2 & $0.5^{++}$ & 77.4 & \multirow[t]{2}{*}{11.3} \\
\hline Control' & 5.1 & $1.7^{++}$ & 66.1 & \\
\hline \multicolumn{5}{|c|}{ Respiratory illnesses" } \\
\hline \multicolumn{5}{|l|}{ Formal housing } \\
\hline Intervention ${ }^{\S}$ & 1.8 & $0.5^{++}$ & 74.2 & \multirow[t]{2}{*}{24.6} \\
\hline Control' & 2.2 & $1.1^{++}$ & 49.6 & \\
\hline \multicolumn{5}{|c|}{ Informal housing } \\
\hline Intervention ${ }^{\S}$ & 1.8 & $0.8^{++}$ & 57.4 & \multirow[t]{2}{*}{37.8} \\
\hline Controls & 5.1 & $4.1^{++}$ & 19.6 & \\
\hline \multicolumn{5}{|c|}{ Skin infections" } \\
\hline \multicolumn{5}{|l|}{ Formal housing } \\
\hline Intervention ${ }^{\S}$ & 1.1 & $0.4^{++}$ & 65.5 & \multirow[t]{2}{*}{39.1} \\
\hline Control & 0.9 & $0.6^{++}$ & 26.4 & \\
\hline \multicolumn{5}{|l|}{ Informal housing } \\
\hline Intervention ${ }^{\S}$ & 1.3 & $0.3^{++}$ & 74.6 & \multirow[t]{2}{*}{-2.5} \\
\hline Control' & 1.3 & $0.3^{++}$ & 77.1 & \\
\hline \multicolumn{5}{|c|}{ *Seasonal: winter/spring = June, July, August, September, October, November. } \\
\hline \multicolumn{5}{|c|}{ 'Incidence per 100 person weeks. } \\
\hline \multicolumn{5}{|c|}{ ‡Gastrointestinal illnesses include: diarrhoea, nausea, vomiting, green stool, sour/foul smelling stool, and mucus in stool. } \\
\hline \multicolumn{5}{|c|}{$\begin{array}{l}\text { SIntervention: hygiene education (behaviour change/PLA) and products (soap, surface cleaner, antiseptic) in 2007. }{ }^{\circ} \text { Control: hygiene education only (behaviour change/PLA) in } \\
2007 .\end{array}$} \\
\hline
\end{tabular}

were 1.64 times more likely to experience gastrointestinal illnesses (HR 1.64, CI 1.32 - 2.03), 4.62 times more likely to experience respiratory illnesses (HR 4.62, CI $4.19-5.09$ ) and 1.29 times more likely to experience skin infections (HR 1.29, CI $1.26-1.32$ ) at the end of study follow-up than their intervention counterparts.

\section{Discussion}

The results of this study demonstrate that communities that received hygiene education plus hygiene products had a significantly lower burden of target illnesses than communities with hygiene education alone. Study results showing illness reductions in INF households receiving hygiene education without hygiene products provided are not surprising, since weekly data collection visits during the intervention phase confirmed the presence and use of soap in those households. Many women in those households also found ways to clean food preparation surfaces and procure antiseptic. The squeezy bottles (home-made handwashing stations made from plastic bottles filled with water with an attached soap sock) were popular, especially with children, and were quickly adopted into consistent behaviour change patterns. The visual presence of the squeezy bottles served as a constant reminder of the need for proper handwashing with soap and running water at critical times. This facilitated and sustained the adopted behaviour change practices.
This study had several limitations. First, a quasi-experimental design was used, and as previously addressed, participants were not randomly selected or randomly assigned to control or intervention groups. Also, true random selection of product placement in participant households was not possible because teamwork between neighbours was essential to reinforce long-term hygiene behaviour change. This design prevented potential cross-contamination of data between households, and household resistance and division within the community. Participants were also purposely assigned to intervention or control groups based on the geographical area in which they resided.

Although control (hygiene education only) communities were comparable demographically to intervention (hygiene education plus hygiene products) communities, there is probably unmeasured confounding that may account for some of the differences reported. Regression models controlled for known measured confounders to minimise differences between communities as much as possible. Another limitation of the study was the use of facilitators both to both implement the study and to collect symptom data. While no monetary incentives were given to facilitators who reported reductions in illness, it is possible that some facilitators were biased in their reporting in order to please study leaders. An additional limitation is the lack of a control group that received no hygiene 
Table 4. Proportional hazard models for gastrointestinal, skin and respiratory illnesses*

\begin{tabular}{|c|c|c|c|c|}
\hline & \multicolumn{2}{|c|}{ Formal housing } & \multicolumn{2}{|c|}{ Informal housing } \\
\hline & HR & $95 \% \mathrm{CI}$ & HR & $95 \% \mathrm{CI}$ \\
\hline \multicolumn{5}{|l|}{ Gastrointestinal illnesses $^{\dagger}$} \\
\hline Hygiene education ${ }^{\ddagger}+$ products $^{\S}$ & 1.00 & - & 1.00 & - \\
\hline Hygiene education ${ }^{\ddagger}$ & 2.46 & $1.17-4.91$ & 1.64 & $1.32-2.03$ \\
\hline Hygiene education ${ }^{\ddagger}(2007)$ & 1.00 & - & 1.00 & - \\
\hline Non-hygiene education` (2006) & 4.63 & $4.10-5.23$ & 3.46 & $2.42-4.96$ \\
\hline \multicolumn{5}{|l|}{ Skin infections ${ }^{11}$} \\
\hline Hygiene education ${ }^{\ddagger}+$ products $^{\S}$ & 1.00 & - & 1.00 & - \\
\hline Hygiene education ${ }^{\ddagger}$ & 0.91 & $0.44-1.85$ & 1.29 & $1.26-1.32$ \\
\hline Hygiene education $^{\ddagger}(2007)$ & 1.00 & - & 1.00 & - \\
\hline Non-hygiene education` (2006) & 2.32 & $1.60-3.36$ & 3.39 & $2.90-3.96$ \\
\hline \multicolumn{5}{|l|}{ Respiratory illnesses } \\
\hline Hygiene education ${ }^{\ddagger}+$ products $^{\S}$ & 1.00 & - & 1.00 & - \\
\hline Hygiene education $^{\ddagger}$ & 4.56 & $1.97-10.54$ & 4.62 & $4.19-5.09$ \\
\hline Hygiene education ${ }^{\ddagger}(2007)$ & 1.00 & - & 1.00 & - \\
\hline Non-hygiene education`(2006) & 2.99 & $1.60-5.58$ & 1.55 & $1.08-2.24$ \\
\hline \multicolumn{5}{|c|}{ "This table shows HRs after controlling for covariates such as age, gender and socio-economic indicators. } \\
\hline \multicolumn{5}{|c|}{${ }^{\dagger}$ Gastrointestinal illnesses: diarrhoea, nausea, vomiting, green stool, sour/foul smelling stool, and mucus in stool. } \\
\hline \multicolumn{5}{|c|}{ ‡Hygiene education: behaviour change/participatory learning and action. } \\
\hline \multicolumn{5}{|c|}{${ }^{\text {HHgiene products (soap, surface cleaner, antiseptic) provided. }}$} \\
\hline \multicolumn{5}{|c|}{$\begin{array}{l}\text { Non-hygiene education: baseline year (2006); no hygiene education; other education only (chronic disease, rodent } \\
\text { control, other). }\end{array}$} \\
\hline
\end{tabular}

behaviour change education or hygiene products.

\section{Conclusion}

While hygiene education alone resulted in meaningful reduction of gastrointestinal and respiratory illnesses and skin infections across all communities, families with hygiene education plus the consistent use of provided hygiene products experienced greater illness reduction in children aged under 5 years. This is the first comprehensive study of which we are aware that has utilised multiple hygiene products in combination with an intensive community-based PLA hygiene behaviour change education approach geared to mobilising communities for improved health and social change. Future efforts will look to documenting the sustainability of the hygiene behaviours and product use in the study communities, as well as diffusion of both into non-study participant households and other nearby communities.
Acknowledgements. We thank our HPP personnel, Phiwe Benya, field data manager Geoff Spires, administrative manager, and Jonnie Spires, budget manager, and all the facilitators and participating households in the communities. We especially thank the community leaders who supported the study and provided access to households in their housing areas. We also thank the Health Department of the City of Cape Town (especially the late Health Director, Ivan Toms) and our other partner organisations for their encouragement and assistance throughout the study period. Finally, we thank John Sowa for his editorial assistance in preparation of the manuscript.

Authors' contributions. ECC, MH, JRR, BTC, KM, JD, TM, JC and CA contributed to the conception and design of the study; $\mathrm{MH}$, TM, JC and CA supervised and conducted the fieldwork, training and data collection; BTC, $\mathrm{JK}$ and ECC conducted data analysis and interpretation; ECC drafted the manuscript; and $\mathrm{MH}, \mathrm{JRR}, \mathrm{KM}, \mathrm{JK}$ and $\mathrm{BC}$ provided critical revision for intellectual content. All authors read and approved the final manuscript.

Competing interests. Authors $\mathrm{MH}, \mathrm{BTC}$, JD, TM, JC and CA were funded primarily by Reckitt Benckiser for their effort in conducting the study. ECC, $\mathrm{MH}$ and BTC received financial support for manuscript preparation from Reckitt Benckiser.

\section{References}

1. Black RE, Morris SS, Bryce J. Where and why are 10 million children dying every year? Lancet 2003;361:2226-2234. [http://dx.doi. org/10.1016/S0140-6736(03)13779-8]

2. World Health Organization. Children's Environmental Health. http://www.who.int/ceh/ en/. (accessed 14 June 2009).

3. O’Ryan M, Prado V, Pickering L. A millennium update on pediatric diarrheal illness in the developing world [electronic version]. Seminars in Pediatric Infectious Diseases 2005;16:125-136. [http://dx.doi.org/10.1053/j.spid.2005.12.008]

4. UNICEF. Pneumonia: The forgotten killer of children. 2006. http://www.childinfo.org/files/ Pneumonia_The_Forgotten_Killer_of_Children. pdf (accessed 15 June 2009).

5. World Health Organization. Children in the new millennium. 2002. http://www.unep.org/ceh/ (accessed 15 June 2009).

6. Luby S, Agboatwall M, Feikin DR, et al. Effect of handwashing on child health: a randomized controlled trial. Lancet 2005;366:225-233. [http:// dx.doi.org/10.1016/S0140-6736(05)66912-7]

7. Luby SP, Agboatwalla M, Painter J, et al. Effects of intensive handwashing promotion on childhood diarrhea in high-risk communities in Pakistan: A randomized controlled trial. JAMA 2004;291:2547-2554. [http://dx.doi. org/10.1001/jama.291.21.2547]

8. Curtis V, Cairncross S. Effects of washing hands with soap on diarrhea risk in the community: a systematic review. Lancet 2003;3:275-280. [http:// dx.doi.org/10.1016/S1473-3099(03)00606-6]

9. Curtis V, Cairncross S, Yonli R. Domestic hygiene and diarrhea - pinpointing the problem. Tropical Medicine and International Health 2000;5(1):22-32. [http://dx.doi.org/10.1046/ j.1365.2000.00512.x]

10. Aubel J. Strategic Report 9: Participatory monitoring \& evaluation for hygiene improvement - a literature review. Environmental Health Project, 2004. http://www.ehproject.org/ PDF/Strategic_papers/SR-9\%20Lit\%20Rev.pdf (accessed 16 June 2009).

11. Howard G, Bogh C, Goldstein G, et al. Healthy Villages - a Guide for Communities and Community Health Workers. Geneva: World Health Organization, 2002. 